\title{
Genetic parentage in the squat lobsters Munida rugosa and $M$. sarsi (Crustacea, Anomura, Galatheidae)
}

\author{
Deborah A. Bailie, Rosaleen Hynes, Paulo A. Prodöhl*
}

School of Biological Sciences, Queen's University Belfast, Medical Biology Centre, 97 Lisburn Road, Belfast BT9 7BL, UK

\begin{abstract}
Munida is the most diverse and cosmopolitan genus of the galatheid squat lobsters. The group has attracted much attention in recent years from both systematic and evolutionary perspectives, yet information on the biology, ecology and evolution of this genus is very limited. We investigated the genetic parentage of 2 North Atlantic species, M. rugosa and M. sarsi, sampled from the Clyde Sea on the west coast of Scotland. Microsatellite markers were used to establish the parental contribution from embryos of berried females (M. rugosa, $\mathrm{n}=25$ and $M$. sarsi, $\mathrm{n}=5$ ). The frequency of multiple paternity observed in both species (86\% for $M$. rugosa and $100 \%$ for $M$. sarsi) is the highest ever reported for any marine crustaceans. Invariably more than 2 sires were involved in each case (minimum of 2 to 3 for $M$. rugosa and 4 for $M$. sarsi). Our findings indicate that multiple paternity is likely to be the norm in both species. Within most multiply sired broods, sire contribution was highly skewed towards a single male (66\% of broods for M. rugosa and $100 \%$ for $M$. sarsi). Furthermore, embryos from different sires were randomly distributed across the female's brood patch. This is the first report of multiple paternity in galatheids. While a number of theories can account for the high incidence of multiple paternity in these species (e.g. convenience polyandry as a result of cryptic female choice, forced copulations, the influence of fishing pressures), at present it is not possible to disentangle their individual and/or combined effects.
\end{abstract}

KEY WORDS: Galatheids · Crustacean mating system · Polyandry $\cdot$ Munida spp.

\section{INTRODUCTION}

The mating behaviour of decapod crustaceans has received considerable attention in recent years (reviewed by Correa \& Thiel 2003, Duffy \& Thiel 2007). Many studies have elaborated on male mating behaviours such as mate guarding and aggression (Wada et al. 1997, Jivoff \& Hines 1998, Rondeau \& Sainte-Marie 2001), or sperm competition. The latter has focused on sperm stratification (Urbani et al. 1998), removal (Beninger et al. 1991) and/or limitation (MacDiarmid \& Butler 1999, Rondeau \& Sainte-Marie 2001, Rubolini et al. 2005). More recently, attention has shifted towards the examination of female behaviour. These studies have addressed questions related to mate selection
(Sainte-Marie et al. 1997), convenience polyandry (Thiel \& Hinojosa 2003) and cryptic female choice (Walker et al. 2002, Thiel \& Hinojosa 2003).

A major difficulty in examining the mating behaviour of marine crustaceans in general is associated with the obvious logistical difficulties of observing mating interactions in their natural environment. The elusive burrowing behaviour and/or nocturnal activities of many species (De Grave \& Turner 1997) further complicate studies on mating. While laboratory experiments have contributed to a better understanding of the mating behaviour of some species (e.g. Urbani et al. 1998, Thiel \& Hinojosa 2003), the mating systems of the majority of crustaceans are still poorly understood. Molecular studies are now providing a powerful alter- 
native for investigating the mating strategies of otherwise elusive and/or difficult target species (e.g. Bilodeau et al. 2005)

Molecular investigations of paternity among marine crustaceans are still rare in comparison with other taxa. With a few exceptions, focusing on brachyuran crabs (Urbani et al. 1998, McKeown \& Shaw 2008), the majority of other studies on marine crustaceans have reported on the incidence of multiple paternity, e.g. porcelain crab Petrolisthes cinctipes (Toonen 2004), crayfish Orconectes placidus (Walker et al. 2002), American lobster Homarus americanus (Gosselin et al. 2005) and ghost shrimp Callichirus islagrande (Bilodeau et al. 2005). Knowledge of mating strategies is particularly relevant for species subject to intense fishing exploitation. For instance, in the American lobster, Gosselin et al. (2005) showed that mating strategies can vary geographically in correlation with different levels of exploitation. The authors suggested that selective fishing pressure for large males could be responsible for such a pattern.

Munida is the most diverse and cosmopolitan genus of the galatheid squat lobsters and, as such, has attracted much attention in recent years from both a systematic and evolutionary perspective. However, information regarding the biology, ecology and evolution of this genus is still limited. Munida rugosa and $M$. sarsi are endemic to the north-eastern Atlantic. They inhabit rocky or soft mud substrata in shelf waters ranging from the shallow to the deeper continental slope. Similar to other Munida species, M. rugosa and M. sarsi are gonochoric, but little is known about the mating behaviour of these species. They are benthic as adults with a planktotrophic larval phase and a developmental period that lasts 3 to 4 mo (Schmidt 1965, Gore 1979, Van Dover \& Williams 1991). Clarification of the mating system of Munida species is now of particular relevance not only because of the increasing target fisheries, but also due to the impact from indirect fishing pressures. In western Scotland, for instance, $M$. rugosa comprises a large component of bycatch from the large-scale commercial Nephrops norvegicus fisheries (Bergmann \& Moore 2001).

Pothanikat (2005) produced the only report detailing the mating behaviour of Munida sarsi, which was based upon laboratory observations. The report stated that coerced mating occurs in the hard-shelled state, with a male holding a female in place with his chelipeds, while trying to insert a spermatophore into the abdominal area of the female with the help of his fifth pereiopods. Females possess no internal organs for sperm storage, and there is no information as to how the female handles the spermatophore or how egg insemination takes place. Following insemination, however, the female's abdomen is cupped under the cephalothorax, forming a spawning chamber where eggs are brooded until they hatch. It is not known whether a female can mate with more than 1 male during a breeding season. While the timing of reproduction is unclear for M. sarsi, in western Scotland $M$. rugosa produce broods from November, with hatching occurring from March to May (Lebour 1930, Zainal 1990, Coombes 2002). Extruded broods contain up to 32000 eggs which are approximately $0.5 \mathrm{~mm}$ in diameter (Wenner 1982, Tapella et al. 2002).

Other crustacean species displaying mating behaviour similar to squat lobsters, including forced copulation (e.g. crayfish) and lack of sperm storage structures (e.g. rock shrimp), are characterised by multiple mating. While it is still unknown as to whether multiple mating behaviour translates into multiple genetic paternity in rock shrimp, this has been confirmed for crayfish (Walker et al. 2002). Thus, we hypothesised that genetic multiple paternity is the mating strategy of the galatheid species investigated. In order to test this hypothesis in Munida rugosa and M. sarsi, we generated and compared microsatellite multilocus genotypes of females and their egg broods in order to deduce paternal contribution.

\section{MATERIALS AND METHODS}

Study sites and collections. Given their elusive nature and habitat preferences (individuals often bury themselves in muddy substrata), it is notoriously difficult to study the mating behaviour of these species in their natural environment. This is particularly the case for egg-carrying females, making them very hard to obtain. Indeed, at least for Munida rugosa, fisheries have been reported to be biased towards males (Coombes 2002). Furthermore, in comparison to $M$. rugosa, $M$. sarsi, as the deeper water species, is considerably more difficult to sample. Thus, despite considerable effort, sampling success for ovigerous females was limited. $M$. rugosa $(\mathrm{n}=25)$ and $M$. sarsi $(\mathrm{n}=5)$ ovigerous females were collected by a $2 \mathrm{~m}$ beam trawl using a $50 \mathrm{~mm}$ mesh in the Clyde Sea (western Scotland) in March 2005 and February 2006. The abdomen and associated eggs from each female were stored in $99 \%$ molecular grade ethanol for subsequent analysis. Species identification was confirmed by genetic screening using diagnostic mtDNA markers (Bailie 2008).

DNA extraction and amplification of microsatellites. Genomic DNA was extracted from the muscle tissue of the ovigerous females as described by Taggart et al. (1992). For Munida rugosa samples, 11 eggs were randomly collected from each of the 4 pleopodal regions (totalling 44 eggs female ${ }^{-1}$ ). A similar sampling 
strategy was carried out for $M$. sarsi, except that 23 eggs were randomly removed from each of the 3 pleopodal regions (totalling 69 eggs female ${ }^{-1}$ ). This sequential egg sampling strategy (i.e. obtaining samples from all pleopodal regions) was carried out in order to account for any potential variation in the timing or order of egg extrusion by females. DNA egg extraction was carried out using a standard Chelex extraction protocol using a 96-well format microtitre plate (information available from the authors upon request).

Microsatellite primer development for both Munida rugosa and $M$. sarsi followed the protocol described by Kijas et al. (1994) based on enriched partial genomic libraries, with modifications as reported by Boston et al. (2009) and McInerney et al. (2008, 2009). Microsatellite-containing regions in the genome of both $M$. rugosa and $M$. sarsi are particularly complex, being characterised by the presence of cryptic repeated elements including transposable elements (Bailie et al. 2010). This makes the development of microsatellites for these species exceptionally difficult. Nevertheless, following the approach outlined by Bailie et al. (2010), 3 informative microsatellite markers were successfully developed for M. rugosa (see Table 1 for details). While no microsatellite markers were successfully developed for M. sarsi, all 3 of the M. rugosa markers were found to cross-hybridise and were used to screen all samples.

Single locus polymerase chain reaction (PCR) amplifications for microsatellite genotyping in a Li-Cor system were carried out in $12 \mu \mathrm{l}$ reaction volumes containing $1 \times$ Promega Taq polymerase buffer, 1.5 to $2.5 \mathrm{mM} \mathrm{MgCl}_{2}$ $100 \mu \mathrm{M}$ dNTP, 1 to $2 \mathrm{pM}$ of each microsatellite primer, 50 ng template DNA and 0.5 to $1 \mathrm{U}$ of Promega Taq DNA polymerase. PCR cycling conditions consisted of 1 cycle at $95^{\circ} \mathrm{C}$ for $5 \mathrm{~min}$, followed by 24 to 28 cycles at $95^{\circ} \mathrm{C}$ for $1 \mathrm{~min}, 42$ to $56^{\circ} \mathrm{C}$ for $1 \mathrm{~min}, 72^{\circ} \mathrm{C}$ for $1 \mathrm{~min}$, followed by 1 cycle of $72^{\circ} \mathrm{C}$ for 5 min (Table 1). Amplified products were denatured at $80^{\circ} \mathrm{C}$ for 3 to $5 \mathrm{~min}$, and $1 \mu \mathrm{l}$ was loaded into a $25 \mathrm{~cm} 6 \% 1 \times$ TBE polyacrylamide gel using a commercially available size-standard ladder for the Li-Cor system (Microstep-13a/b and 20a, Microzone) to accurately estimate the size of allelic fragments. Gels were run on the Li-Cor system at a constant power of $40 \mathrm{~W}$ at a temperature of $\sim 50^{\circ} \mathrm{C}$ for 1 to $2 \mathrm{~h}$. Genotypic scoring was carried out using the computer software Gene Profiler (Scanalytics).

Statistical analysis. The power of the 3 microsatellite markers to detect multiple paternity was assessed through simulation analysis as implemented in the Probability to Detect Multiple Matings (PRDM) program (Neff \& Pitcher 2002). This simulation takes into consideration the potential number of sires, degree of paternal skew and brood size analysed under a range of possible mating scenarios across both species. Mating scenarios, which take into consideration equal, moderately skewed and highly skewed male breeding success, were chosen to reflect both information available from crustacean mating system studies (Walker et al. 2002, Bilodeau et al. 2005, Yue et al. 2010) and recommendations by Neff \& Pitcher (2002). Allelic frequency population data for Munida rugosa and $M$. sarsi samples from the same area were available from a parallel study into the population structure of both species, which was carried out within our research group.

The occurrence of multiple paternity of a brood was established by the occurrence of more than 2 paternal alleles across at least 2 loci (to allow for the possibility of mutation at 1 locus). On confirmation of multiple paternity, GERUD (Jones 2001) was used to estimate the minimum number of possible males, to reconstruct all possible male genotypes and to rank the likelihood of each male's contribution to the brood in correlation with the known maternal genotypes. When more than 2 paternal alleles were identified at a single locus only, $\chi^{2}$ statistics were used to test whether the remaining 1 or 2 loci displayed evidence for significant deviations from expected Mendelian genotypic ratios.

Table 1. Primer details of microsatellite loci developed in this study. Product size represents the size in base pairs (bp) of the cloned allele from which primers were designed, annealing temperature (Ta), $\mathrm{MgCl}_{2}$ concentration and number of PCR cycles used in amplification reactions with this Ta (denaturation and extension temperatures were 95 and $72^{\circ} \mathrm{C}$, respectively, for all primer sets). F: forward; R: reverse. ${ }^{*}$ : specific primer of the pair labelled with fluorescent dye

\begin{tabular}{|c|c|c|c|c|c|}
\hline Primer & Sequence $5^{\prime}$ to $3^{\prime}$ & Product size (bp) & Ta $\left({ }^{\circ} \mathrm{C}\right)$ & $\mathrm{MgCl}_{2}(\mathrm{mM})$ & No. cycles \\
\hline MR62F & TAAACGACCAATCCCATTAGAC & \multirow[t]{2}{*}{154} & \multirow[t]{2}{*}{52} & \multirow[t]{2}{*}{1.5} & \multirow[t]{2}{*}{28} \\
\hline MR62R* & TATATTTGGAGTAAAGTGG & & & & \\
\hline${\mathrm{MR} 63 \mathrm{~F}^{*}}^{2}$ & TCTTGAGAAAGATAGAAATAT & \multirow[t]{2}{*}{132} & \multirow[t]{2}{*}{42} & \multirow[t]{2}{*}{2.5} & \multirow[t]{2}{*}{25} \\
\hline MR63R & CTTGCGCAAGCGGGAATAA & & & & \\
\hline MR778F & GGAAACCAACTCATTATTACTTAC & \multirow[t]{2}{*}{135} & \multirow[t]{2}{*}{56} & \multirow[t]{2}{*}{2.5} & \multirow[t]{2}{*}{24} \\
\hline MR778R* & CCGTGGCCACCCCCTTAG & & & & \\
\hline
\end{tabular}




\section{RESULTS}

Although very difficult to develop, the resulting 3 microsatellite marker loci (MR62, MR63 and MR778) were found to be sufficiently informative for parentage analysis in both Munida rugosa and $M$. sarsi. Summary genetic statistics for the population samples screened for both species (M. rugosa: no. of individuals, $\mathrm{n}=80$ and $M$. sarsi: $\mathrm{n}=18$ from an ongoing population study) are reported in Table 2. MR778 was found to be monomorphic in $M$. sarsi; thus, the screening of $M$. sarsi broods was conducted with only 2 microsatellite loci (MR62 and MR63). No significant departure from HardyWeinberg equilibrium was observed globally in either species. No genotypic disequilibrium was observed between loci, and no null alleles were detected in the present study.

While only 2 (Munida sarsi) or 3 ( $M$. rugosa) microsatellite markers were used for parentage analysis, these invariably displayed adequate power $(27$ to $100 \%$ ) for detecting multiple paternity in both species depending on the mating scenario considered (Table 3).

Not surprisingly, the power to detect multiple paternity increases with brood size. The logistical difficulties in characterising genotypes of the high number produced by some crustacean species has resulted in studies (e.g. Urbani et al. 1998, Walker et al. 2002, Gosselin et al. 2005) implementing a pooling approach. The drawback of such an approach is that the true number of males can be significantly underestimated, particularly if the male contribution is highly skewed; therefore, we elected to screen individual eggs.

Table 2. Munida rugosa and M. sarsi. Summary statistics for population samples of $M$. rugosa (no. of individuals, $\mathrm{n}=80$ ) and $M$. sarsi $(\mathrm{n}=18)$. Allelic diversity $(K)$ observed and expected heterozygosities ( $H_{\text {obs }}$ and $H_{\text {exp }}$, respectively) for 3 microsatellite loci

\begin{tabular}{|llrcl|}
\hline Species & Locus & $K$ & $H_{\text {obs }}$ & $H_{\exp }$ \\
\hline M. rugosa & MR62 & 14 & 0.845 & 0.825 \\
& MR63 & 6 & 0.436 & 0.445 \\
& $M R 778$ & 7 & 0.493 & 0.496 \\
M. sarsi & MR62 & 14 & 0.96 & 0.92 \\
& MR63 & 4 & 0.21 & 0.27 \\
& $M R 778$ & \multicolumn{3}{c}{ Monomorphic } \\
\hline
\end{tabular}

The average number of eggs (32 for Munida rugosa and 40 for M. sarsi) for which consistent genotypic data were obtained per brood was adequate for detecting multiple paternity with a PRDM between 60 and $100 \%$ across both species (Table 3). Dependent on the skew detected, the average number of eggs $(N)$ screened does not greatly improve the likelihood of detecting multiple paternity. For example, for $M$. rugosa with a mating scenario of slight paternal skew (e.g. 67:33), the power to detect paternity when screening 20 eggs is $87 \%$, with increased screening of 86 eggs only improving the power to $89 \%$. This indicates that the power of detecting multiple paternity is surprisingly high despite the low number of markers available. The number of additional paternal alleles observed among the offspring of $M$. rugosa broods provided evidence of multiple paternity by, firstly, displaying more than 2 paternal alleles in more than 1 locus, or when more than 2 paternal alleles were identified at a single locus deviating from the Mendelian inheritance of a 1:1 ratio (Table 4).

Multiple paternity was evident in $21(84 \%)$ of the Munida rugosa families. Thirteen females (52\%) mated with a minimum of 2 sires while the remaining $8(32 \%)$ mated with a minimum of 3 (Table 4$)$. Given 
Table 4. Munida rugosa. (A) Allelic inheritance microsatellite DNA profiles for 25 berried females. In each case, allelic profiles, identified by the length of the amplification product (in bp), result from the screening of an average of 32 fertilised eggs. Female alleles and putative sire alleles (in italics) are reported per locus. (B) Average minimum number of males per family with which each female must have mated in order to generate the observed allelic distribution among the offspring is also reported. FG: female genotype

\begin{tabular}{|c|c|c|c|c|c|c|c|}
\hline \multirow{3}{*}{$\begin{array}{l}\text { (A) } \\
\text { M. rugosa } \\
\text { female } \\
\text { ID }\end{array}$} & & \multirow{3}{*}{$\begin{array}{c}\text { Min. } \\
\text { no. } \\
\text { males }\end{array}$} \\
\hline & \multirow{2}{*}{\multicolumn{2}{|c|}{$\begin{array}{l}\text { MR62 } \\
\quad \text { Paternal alleles }\end{array}$}} & \multicolumn{2}{|c|}{$\begin{array}{c}\text { Microsatellite loci } \\
\text { MR63 }\end{array}$} & \multicolumn{2}{|c|}{$M R 778 \longrightarrow$} & \\
\hline & & & FG & Paternal alleles & FG & Paternal alleles & \\
\hline $1^{\mathrm{a}, \mathrm{b}}$ & 204,232 & $204,212,240$ & 133,133 & 133 & 135,135 & $127,131,135,139$ & 3 \\
\hline $2^{\mathrm{b}}$ & 212,212 & $204,212,220$ & 133,133 & 133,137 & 123,131 & 135 & 2 \\
\hline 3 & 204,204 & 204,212 & 133,133 & 133 & 127,135 & 135 & 1 \\
\hline $4^{\mathrm{a}, \mathrm{b}}$ & 204,204 & $204,208,212,240$ & 133,137 & 133,137 & 131,135 & $127,131,135,139$ & 3 \\
\hline $5^{a, b}$ & 212,220 & $212,220,208,216,232$ & 133,137 & 133,137 & 135,135 & 135 & 3 \\
\hline $6^{\mathrm{b}}$ & 204,240 & $204,240,212$ & 133,133 & 133,137 & 131,135 & 127,135 & 2 \\
\hline $7^{\mathrm{a}, \mathrm{b}}$ & 208,220 & $200,204,208,216$ & 133,133 & $133,137,141$ & 135,135 & 131,135 & 3 \\
\hline $8^{\mathrm{b}}$ & 196,208 & $196,212,240$ & 133,137 & 133,137 & 135,151 & 135 & 2 \\
\hline $9^{a, b}$ & 212,224 & $196,204,212,228$ & 133,137 & 133,137 & 131,139 & $107,131,135,139$ & 3 \\
\hline 10 & 212,212 & 206, 208 & 133,137 & 133,141 & 135,139 & 131,135 & 1 \\
\hline 11 & 204,204 & $204,212,240$ & 133,137 & 133,137 & 135,135 & $131,135,139$ & 2 \\
\hline $12^{\mathrm{b}}$ & 196,204 & 204,212 & 133,133 & $133,125,141$ & 135,135 & 131,135 & 2 \\
\hline $13^{\mathrm{b}}$ & 204,212 & 204,208 & 133,137 & 141 & 135,135 & $127,135,139$ & 2 \\
\hline $14^{\mathrm{a}}$ & 204,208 & $204,208,212,236$ & 133,133 & 133 & 135,135 & $127,135,139$ & 2 \\
\hline $15^{\mathrm{b}}$ & 212,216 & $204,212,220$ & 133,133 & 133,141 & 131,139 & 135,139 & 2 \\
\hline $16^{\mathrm{b}}$ & 204,212 & 204,212 & 133,137 & 133,137 & 135,135 & $131,135,139$ & 2 \\
\hline $17^{\mathrm{b}}$ & 204,236 & $208,212,216$ & 133,133 & 133,137 & 135,135 & 135,139 & 2 \\
\hline $18^{\mathrm{b}}$ & 204,216 & 204 & 137.137 & 133 & 131,135 & $127,135,139$ & 2 \\
\hline $19^{\mathrm{b}}$ & 212,240 & $208,212,220,228,232$ & 125,129 & 133 & 135,135 & 135,139 & 3 \\
\hline $20^{\mathrm{a}, \mathrm{b}}$ & 212,2362 & $00,204,208,212,220,236$ & 133,137 & 133,137 & 135,139 & $127,135,139$ & 3 \\
\hline $21^{\mathrm{a}, \mathrm{b}}$ & 204,208 & $204,212,216,220,232$ & 133,133 & 133 & 135,135 & $127,135,139$ & 3 \\
\hline 22 & 212,240 & 212 & 133,133 & 133,145 & 135,135 & 135 & 1 \\
\hline $23^{\mathrm{a}}$ & 204,204 & $204,208,212$ & 133,133 & 133,137 & 135,135 & $127,131,135$ & 2 \\
\hline $24^{\mathrm{a}}$ & 204,204 & $204,208,212$ & 133,137 & $133,125,145$ & 135,135 & $131,135,139$ & 2 \\
\hline 25 & 204,208 & 204,240 & 133,137 & 133,137 & 135,135 & 127,135 & 1 \\
\hline \multirow[t]{4}{*}{ (B) } & \multicolumn{2}{|c|}{ Min. no. sires } & broods & \multicolumn{2}{|c|}{ No. broods (= mating females) } & & \\
\hline & & 32 & & 8 & & & \\
\hline & & 52 & & 13 & & & \\
\hline & & 16 & & 4 & & & \\
\hline
\end{tabular}

that evidence for multiple paternity in $44 \%$ of the cases ( 11 females) is provided by more than 1 locus or a single locus with more than 2 paternal alleles, it is unlikely that this is an artefact of high levels of mutation.

In $66.7 \%$ of the detected cases of multiple paternity, paternal contribution was often significantly skewed (t-test, p < 0.001) towards 1 particular male (i.e. sum of 38.2 and $28.5 \%$ from mating scenarios 95:5 and 86:8:6, respectively; Table 5). The estimated PDRM probability of detecting more than 1 male within a given family using these markers ranged from 46 to $93 \%$ (Table 5). The numbers observed in the present study are within the upper extreme of this range (i.e. $84 \%$ resulting from the sum of 32 and $52 \%$ for 8 and 13 families associated with 3 and 2 sires, respectively, see Table 4).
Table 5. Munida rugosa. Summary of the estimated frequency of multiple paternity. Six scenarios were considered for the number of fathers and their reproductive skew. The probability of detecting this mating scenario in the current $M$. rugosa dataset was simulated by the Probability to Detect Multiple Matings (PRDM). Values discussed in the text are in bold

\begin{tabular}{|lcccc|}
\hline $\begin{array}{l}\text { No. } \\
\text { fathers }\end{array}$ & $\begin{array}{c}\text { Paternal } \\
\text { skew }\end{array}$ & $\begin{array}{c}\text { No. } \\
\text { families }\end{array}$ & $\begin{array}{c}\text { Frequency of } \\
\text { observed } \\
\text { pattern (\%) }\end{array}$ & $\begin{array}{c}\text { Probability } \\
\text { of detecting } \\
\text { pattern }\end{array}$ \\
\hline 2 & $50: 50$ & 1 & 4.7 & $\mathbf{0 . 7 5 4}$ \\
& $67: 33$ & 3 & 14.4 & 0.748 \\
& $95: 5$ & 8 & $\mathbf{3 8 . 2}$ & $\mathbf{0 . 4 6 6}$ \\
3 & $33: 33: 33$ & 1 & 4.7 & 0.931 \\
& $57: 28.5: 14.5$ & 2 & 9.5 & 0.922 \\
& $86: 8: 6$ & 6 & $\mathbf{2 8 . 5}$ & $\mathbf{0 . 7 8 3}$ \\
& & & & \\
\hline
\end{tabular}




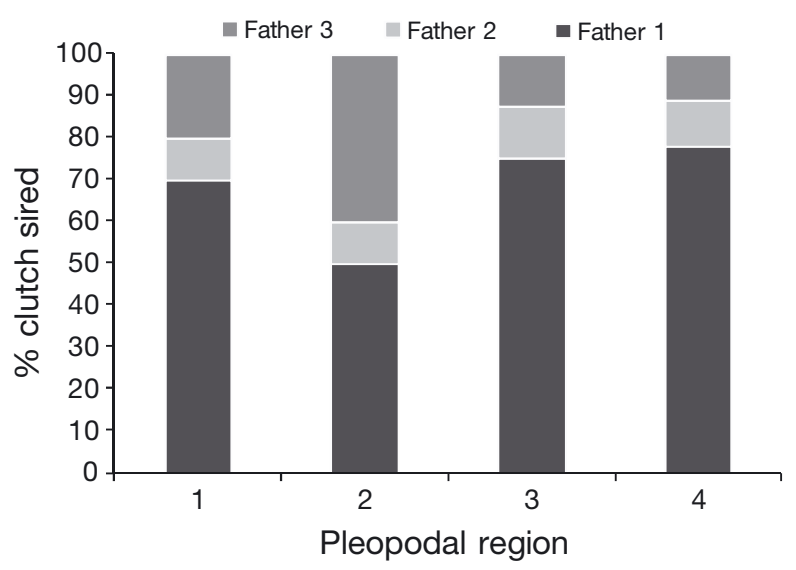

Fig. 1. Munida rugosa. Paternal contributions made to Family 7 female's clutch based upon the highest likelihood ranked combination of paternal males through GERUD analysis. In this case, contribution of presumed males (represented by varying shades of grey) is given by pleopodal region. Three sires were identified and contributed to each of the 4 pleopodal segments

Conversely, for the remaining $25 \%$ of cases, the markers provide little power to detect multiple paternity, hence potentially explaining the instances of single paternity observed (identified in $16 \%$ of cases, see Table 4). The probability of detecting multiple paternity decreases (e.g. 46 to $78 \%$ when taking into account 2 to 3 males, respectively) with increasing paternal skew (Table 5). However, despite this and extreme paternal skew (i.e. $>95 \%$ ), multiple paternity was detected in two-thirds $(66.7 \%)$ of Munida rugosa families in this investigation.

The microspatial distribution of contributing males in Munida rugosa broods exhibiting multiple paternity (86\%) was evident in each of the 4 pleopodal segments. It was also clear that second and third males

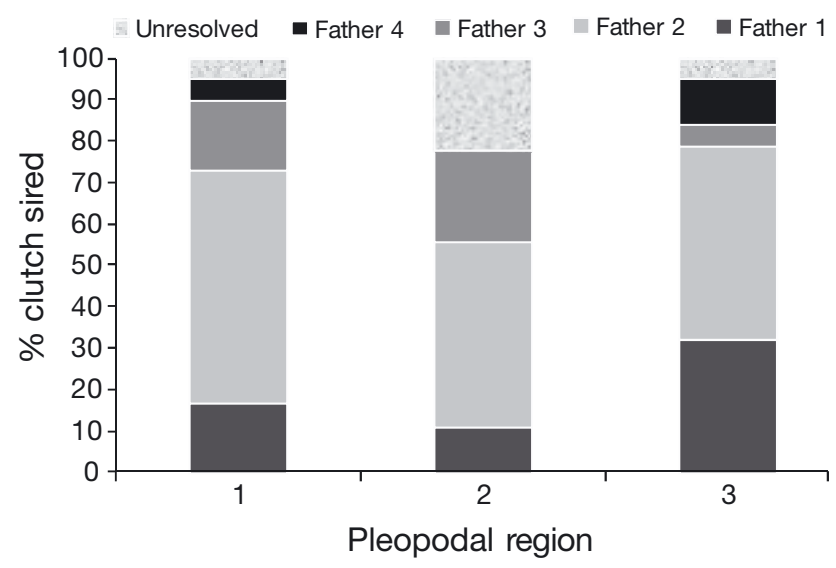

Fig. 2. Munida sarsi. Paternal contributions made to Family 5 female's clutch based upon the highest likelihood ranked combination of paternal males through GERUD analysis. In this case, contribution of presumed males (represented by varying shades of grey) is given by pleopodal region. Four sires were identified in this family, and eggs unable to be assigned to an individual male due to the allelic makeup of the offspring and other putative males were classified as 'unresolved'

(unless very underrepresented) also contributed to 2 to 3 of the 4 pleopodal segments in $52 \%$ of broods (e.g. Fig. 1), thereby suggesting the possibility of egg mixing or simultaneous egg extrusion.

In congruence with Munida rugosa, the allelic distribution in all 5 M. sarsi broods (100\%) provided unequivocal evidence of multiple paternity. A minimum of 4 sires were required to explain each brood's allelic make up (Table 6). This contrasts with the results observed for $M$. rugosa, where a maximum of 3 sires was detected. Similar to what was observed in M. rugosa, there appears to be considerable variation in the relative contribution of individual males siring

Table 6. Munida sarsi. Summary of allelic inheritance from a sample of an average of 40 brooded offspring from each of 5 berried females. Female alleles and male alleles (in italics) are reported (excluding fertilised eggs for which parentage could not be unambiguously resolved among putative males). Each female must have mated with a minimum of 4 males in order to generate the observed allelic distribution among the offspring (as estimated using GERUD). All families had multiple paternity detected at more than 1 locus or with more than 3 paternal alleles at a single locus, and the likelihood of a false result due to mutation is decreased in these cases. In addition, all families had multiple paternity detected by significant deviations from expected Mendelian genotypic ratios

\begin{tabular}{|c|c|c|c|c|}
\hline \multirow{3}{*}{$\begin{array}{l}\text { M. sarsi } \\
\text { female ID }\end{array}$} & \multirow{3}{*}{ Female genotype } & \multirow{3}{*}{ MR62 } & \multirow{2}{*}{\multicolumn{2}{|c|}{ MR63 }} \\
\hline & & & & \\
\hline & & & Female genotype & Paternal alleles \\
\hline 1 & 192,212 & $188,192,200,212,216,224,232$ & 129,133 & 129,145 \\
\hline 2 & 188,224 & $148,168,172,188,196,200,224,284$ & 129,129 & $117,129,141$ \\
\hline 3 & 212,220 & $188,192,200,212,216,220,236$ & 129,129 & $129,133,141$ \\
\hline 4 & 220,224 & $188,212,220,224,244,308$ & 129,133 & $117,129,133,145$ \\
\hline 5 & 200,328 & $200,236,316,324$ & 129,129 & $129,137,141$ \\
\hline
\end{tabular}


the offspring of particular females. A single male was highly favoured in all mating scenarios, but the varying proportions of contributions made by subsequent males differed. As for $M$. rugosa, when more than 1 male was present (in all 5 families) each male's contribution was evident in each of the 3 pleopodal segments (Fig. 2), with few exceptions.

\section{DISCUSSION}

Given the difficulties in obtaining microsatellites for these and possibly other galatheid species (Bailie et al. 2010), those identified in the present study are not only extremely valuable but are currently the only markers available for these galatheids. In the present study, these 3 markers were found to be sufficiently polymorphic to detect genetic contribution from multiple males. Invariably, while more than 1 marker is needed to discard mutation bias, the detection of multiple paternity does not require a large number of marker loci. Thus, the number of markers used in this case is comparative to the majority of other crustacean molecular paternity studies published to date (e.g. Urbani et al. 1998, Walker et al. 2002, Streiff et al. 2004, Toonen 2004, Bilodeau et al. 2005, Gosselin et al. 2005). The secretive and nocturnal nature of galatheids (De Grave \& Turner 1997) makes behavioural observations difficult. Molecular work has proven essential to provide novel information on the mating strategy of these elusive galatheids. Indeed, the present study provides the first genetic evidence for the occurrence of multiple paternity in any Galatheidae species.

In addition to identifying multiple paternity, this is the first investigation to demonstrate that polyandry is the predominant mating strategy in Munida rugosa and $M$. sarsi from the Clyde Sea area. We argue that the few instances of monogamy identified in M. rugosa $(14 \%)$ are likely to be an artefact of the comparatively low power of markers employed in this particular case. Thus, the frequency of multiple paternity observed is likely to be an underestimation of the true extent for this species in the wild. The identification of a higher number of contributing males to broods in $M$. sarsi in comparison with that seen in $M$. rugosa broods is interesting. While we only examined $5 \mathrm{M}$. sarsi broods, this species occurs at higher densities than $M$. rugosa (Hartnoll et al. 1992), making it feasible for M. sarsi to have more opportunity for male encounters.

The findings of this investigation (i.e. polyandry) are comparable to what has been observed in the majority of other crustacean species including the thalassinidean ghost shrimp Callichirus islagrande (Bilodeau et al. 2005), American lobster Homarus americanus (Gosselin et al. 2005), rock shrimp Rhynchocinetes typus (Thiel \& Hinojosa 2003), porcelain crab Petrolisthes cinctipes (Toonen 2004), snow crab Chionoecetes opilio (Urbani et al. 1998) and crayfish Orconectes placidus (Walker et al. 2002). Contrary to these studies, however, the incidence of polyandry in both Munida rugosa $(84 \%)$, but in particular $M$. sarsi $(100 \%)$, is higher than that observed in other crustacean species. Prior to the present study, the highest levels of multiple paternity have been observed in species such as $O$. placidus $(60 \%$, Walker et al. 2002), porcelain crab (80\%, Toonen 2004) and Norway lobster Nephrops norvegicus (54\%, Streiff et al. 2004).

Previous reports of multiple paternity in crustaceans have elaborated on a number of explanations for this behaviour, including convenience polyandry, cryptic female choice (by re-mating, discarding sperm from selected males or delaying ovulation) or forced copulations (Thiel \& Hinojosa 2003, Walker et al. 2002). Alternatively, the reduced number of males resulting from sex-biased fisheries may result in a female mating with more than 1 male in order to obtain sufficient sperm to fertilise her brood (Gosselin et al. 2005). The multiple mating identified in Munida rugosa and $M$. sarsi females is compatible with 1 or more of these hypotheses. Limited laboratory observations have shown that forced copulations occur in M. sarsi (Pothanikat 2005), while sex-biased fisheries have also been reported for M. rugosa (Coombes 2002).

Ra'anan \& Sagi (1985) suggested that forced copulations, where males transfer sperm externally to the females, are common in crustacean species. This argument is corroborated by a number of observations of this behaviour in species such as the crayfish Austropotamobius italicus (Rubolini et al. 2006), rock shrimp (Thiel \& Hinojosa 2003) and Munida sarsi (Pothanikat 2005). It is interesting to note that for species where forced copulations-involving external sperm transfer and external fertilisation-occur, multiple mating has often been observed (Walker et al. 2002, Thiel \& Hinojosa 2003). It is possible that forced copulations may be triggered by a number of factors. For instance, males might have to force copulation because hard-shelled females do not require protection, and hence can potentially afford to be choosy. Alternatively, following Bateman's principle, males might want to increase their biological fitness by mating with a large number of females.

While the incidence of forced copulations by males of Munida species implies strong male influence on mating behaviour, female choice cannot be underestimated. For the rock shrimp, based on behavioural observations, Thiel \& Hinojosa (2003) suggested that cryptic female choice plays an important part in this species' mating behaviour. The authors reported that Rhynchocinetes typus actively chooses male sper- 
matophores favouring larger individuals. Thus, at least for this species, females can influence the breeding success of particular males even though copulations were forced. Therefore, for rock shrimp species, direct genetic benefits might be the main factor favouring this particular mating strategy (reviewed by Jennions \& Petrie 2000).

In order to counteract male bias through forced copulations and to reduce the risk of injury, it is possible that females are able to make postcopulatory choices by selecting spermatophores from large males. This mechanism aids to increase genetic diversity and viability of the females' offspring, while also ensuring the provision of an adequate amount of sperm for the fertilisation of their broods. While sperm competition and/or sperm pack removal by male competitors cannot be excluded, it is also possible that the paternal skew in the parentage assignment observed in Munida species is due to female cryptic choice. Therefore, it is feasible that females could potentially favour 'better' males.

The already established squat lobster fisheries in western Scotland and reported squat lobster discards through Nephrops fisheries (Bergmann \& Moore 2001) have the potential to perturb the mating system of the species. Direct or indirect fishing efforts may affect the operational sex ratio (OSR) of the Munida species, which can influence behavioural aspects of each sex. This is particularly true when one sex is gathered in higher numbers than the other, causing a skew in the sex ratio, thus increasing competition for each respective sex.

Studies of population biology conducted by Coombes (2002) suggested that male Munida rugosa were dominant in particular months of the year (i.e. February and June), and another study found comparatively reduced numbers of females in May and August (Hartnoll et al. 1992). Although it is unlikely that this reflects a true difference in sex ratio, the skew may represent cryptic behavioural responses related to the reproductive and moulting cycle, resulting in males being more vulnerable to fishing pressures in particular months. The incidence of multiple paternity may be influenced by geographical location or fisheries' exploitation levels as suggested for the American lobster (Gosselin et al. 2005). The removal of large males by fisheries forces females to multiply mate with smaller males in order to get enough sperm to fertilise their broods. Males have also been reported to economise their sperm (MacDiarmid \& Butler 1999, Rondeau \& Sainte-Marie 2001, Rubolini et al. 2005). This behaviour also forces females to mate with more than 1 male to ensure fertilisation of their broods. Consequently, the Clyde Sea fisheries may affect the mating system observed in
Munida species in that area as compared to that seen in unexploited areas.

While external fertilisation may be followed by either simultaneous or consecutive egg extrusion in correspondence to each spermatophore, it is currently not known whether galatheid females can handle more than 1 spermatophore at any given time. Consecutive spermatophore handling and egg extrusion has been reported in the rock shrimp (Thiel \& Hinojosa 2003), whereas a simultaneous mode of handling has been recorded in the mole crab Emeritus asiaticus (Subramoniam 1977, 1979). If females are capable of handling more than 1 spermatophore as eggs are being extruded, then males may compete by removing other males' sperm (Beninger et al. 1991). Thus, despite theories of cryptic female choice, the observed paternal skew could alternatively be the result of last male precedence, as has previously been reported in the snow crab (Sévigny \& Sainte-Marie 1996). Therefore, the identification of significantly highly skewed broods ( 1 male sired $>86 \%$ of the brood; $66 \%$ of Munida rugosa families and $100 \%$ of $M$. sarsi families) could be the result of cryptic female choice and/or last male precedence and/or sperm competition.

For both Munida species reported in the present study, the offspring from different sires were randomly distributed among the females' brood-patch. While such an observation is compatible with a simultaneous fertilisation mode, the alternative hypothesis of sequential egg extrusion cannot be ruled out if egg mixing occurs in the brood. Considering that egg mixing may result in egg loss, it is reasonable to assume that simultaneous fertilisation is the most likely scenario for these species.

\section{CONCLUSION}

The genetic parentage analyses conducted in this study have demonstrated that (1) both Munida rugosa and M. sarsi mate multiply with 2 to 4 sires, as respectively 86 and $100 \%$ of broods were multiply sired; (2) the offspring of different males were distributed throughout the females' pleopods; and (3) in most broods analysed (66 and $100 \%$, respectively), it was evident that they were significantly highly skewed towards a single male. In this particular study, we cannot differentiate between all the theories discussed (convenience polyandry as a result of cryptic female choice, forced copulations and/or the influence of fishing pressures) or a combination thereof. Future work would benefit from comparisons of mating scenarios from fisheries exploited and unexploited areas and more detailed behavioural observations to disentangle the possible theories discussed. 
Acknowledgements. This work was funded by a grant from the Department of Agriculture and Rural Development (DARD), Northern Ireland. Many thanks to T. Claverie from University of Glasgow for providing squat lobster samples from western Scotland. Crustacean genetics research in P.A.P.'s laboratory is currently supported by the Beaufort Marine Research Award in Fish Population Genetics carried out under the Sea Change Strategy and the Strategy for Science Technology and Innovation (2006-2013), with the support of the Marine Institute, funded under the Marine Research Sub-Programme of the National Development Plan 2007-2013.

\section{LITERATURE CITED}

Bailie DA (2008) Phylogeny, population genetics and mating strategies of the squat lobster species Munida rugosa and Munida sarsi (Crustacea, Decapoda, Galatheidae). PhD thesis, Queen's University, Belfast

Bailie DA, Fletcher H, Prodöhl PA (2010) High incidence of cryptic repeated elements in microsatellite flanking regions of galatheid genomes and its practical implications for molecular marker development. J Crustac Biol 30: 664-672

Beninger PG, Elner RW, Poussarty Y (1991) Gonopods of the majid crab Chionoecetes opilio (O. Fabricius). J Crustac Biol 11:217-223

Bergmann M, Moore PG (2001) Survival of decapod crustaceans discarded in the Nephrops fishery of the Clyde Sea area, Scotland. ICES J Mar Sci 58:163-171

Bilodeau AL, Felder DL, Neigel JE (2005) Multiple paternity in the thalassinidean ghost shrimp, Callichirus islagrande (Crustacea: Decapoda: Callianassidae). Mar Biol 146: 381-385

Boston ESM, Montgomery WI, Prodöhl PA (2009) Development and characterisation of 11 polymorphic compound tetranucleotide microsatellite loci for the Leisler's bat, Nyctalus leisleri (Vespertilionidae, Chiroptera). Conserv Genet 10:1501-1504

Coombes JCH (2002) Aspects of the biology and fisheries ecology of the velvet swimming crab, Necora puber (L.), and the squat lobsters Munida rugosa (Fabricius) and $M$. sarsi Huss (Crustacea: Decapoda) in Scottish waters. PhD dissertation, University of Glasgow

Correa C, Thiel M (2003) Mating systems in caridean shrimp (Decapoda: Caridae) and their evolutionary consequences for sexual dimorphism and reproductive biology. Rev Chil Hist Nat 76:187-203

De Grave S, Turner JT (1997) Activity rhythms of the squat lobsters, Galathea squamifera and G. strigosa (Crustacea, Decapoda, Anomura) in south-west Ireland. J Mar Biol Assoc UK 77:273-276

Duffy JE, Thiel M (eds) (2007) Evolutionary ecology of social and sexual systems: crustaceans as model organisms. Oxford University Press, New York, NY

Gore RH (1979) Larval development of Galathea rostrata under laboratory conditions, with a discussion of larval development in the Galatheidae (Crustacea Anomura). Fish Bull 76:781-806

Gosselin T, Sainte-Marie B, Bernatchez L (2005) Geographic variation of multiple paternity in the American lobster Homarus americanus. Mol Ecol 14:1517-1525

Hartnoll RG, Rice AL, Attrill MJ (1992) Aspects of the biology of the galatheid genus Munida (Crustacea, Decapoda) from the Porcupine Seabight, Northeast Atlantic. Sarsia $76: 231-246$
Jennions MD, Petrie M (2000) Why do females mate multiply? A review of the genetic benefits. Biol Rev Camb Philos Soc $75: 21-64$

Jivoff P, Hines AH (1998) Female behaviour, sexual competition and mate guarding in the blue crab, Callinectes sapidus. Anim Behav 55:589-603

> Jones A (2001) GERUD 1.0: a computer program for the reconstruction of parental genotypes from progeny arrays using multilocus DNA data. Mol Ecol Notes 1:215-218

Kijas JMH, Fowler JCS, Gabett CA, Thomas MR (1994) Enrichment of microsatellites from the citrus genome using biotinylated oligonucleotide sequences bound to streptavidin-coated magnetic particles. Biotechniques 16:657-662

Lebour M (1930) The larvae of the Plymouth Galatheidae. I. Munida banffica, Galathea strigosa and Galathea dispersa. J Mar Biol Assoc UK 17:175-188

MacDiarmid AB, Butler MJ (1999) Sperm economy and limitation in spiny lobsters. Behav Ecol Sociobiol 46:14-24

> McInerney CE, Allcock AL, Johnston MP, Prodöhl PA (2008) Characterisation of polymorphic microsatellites for the periwinkle gastropod, Littorina littorea (Linnaeus, 1758) and their cross-species amplification in four congeners. Conserv Genet 10:1417-1420

> McInerney CE, Allcock AL, Johnson MP, Prodöhl PA (2009) Characterization of polymorphic microsatellites for the rough periwinkle gastropod, Littorina saxatilis (Olivi, 1792) and their cross-amplification in four congeners. Conserv Genet 10:1989-1992

- McKeown NJ, Shaw PW (2008) Polymorphic nuclear microsatellite loci for studies of brown crab, Cancer pagurus L. Mol Ecol Resour 8:653-655

Neff BD, Pitcher TE (2002) Assessing the statistical power of genetic analyses to detect multiple mating in fish. J Fish Biol 61:739-750

Pothanikat RME (2005) The behaviour and ecology of Munida rugosa and Munida sarsi. PhD dissertation. Queen's University, Belfast

Ra'anan Z, Sagi A (1985) Alternative mating strategies in male morphotypes of the freshwater prawn Macrobrachium rosenbergii (De Man). Biol Bull (Woods Hole) 169:592-601

Rondeau A, Sainte-Marie B (2001) Variable mate guarding time and sperm allocation by male snow crabs (Chinoecetes opilio) in response to sexual competition, and their impact on the mating success of females. Biol Bull (Woods Hole) 201:204-217

Rubolini D, Galeotti P, Ferrari G (2006) Sperm allocation in relation to male traits, female size, and copulation behaviour in a freshwater crayfish. Behav Ecol Sociobiol 60: $212-219$

Sainte-Marie B, Sevigny JM, Gauthier Y (1997) Laboratory behaviour of adolescent and adult males of the snow crab (Chionoecetes opilio) (Brachyura: Majidae) mated noncompetitively and competitively with primiparous females. Can J Fish Aquat Sci 54:239-248

Schmidt WL (1965) Crustaceans. The University of Michigan Press, Ann Arbor, MI

Sévigny JM, Sainte-Marie B (1996) Electrophoretic data support the last-male sperm precedence hypothesis in the snow crab, Chionoecetes opilio (Brachyura: Majidae). J Shellfish Res 15:437-440

> Streiff R, Mira S, Castro M, Cancela ML (2004) Multiple paternity in Norway lobster (Nephrops norvegicus L.) assessed with microsatellite markers. Mar Biotechnol 6:60-66

> Subramoniam $\mathrm{T}$ (1977) Aspects of sexual biology of the anomuran crab, Emerita asiatica. Mar Biol 43:369-377 
Subramoniam T (1979) Some aspects of reproductive ecology of a mole crab Emerita asiatica (Milne Edwards). J Exp Mar Biol Ecol 36:259-268

Taggart JB, Hynes RA, Prodohl PA, Ferguson A (1992) A simplified protocol for routine total DNA isolation from salmonid fishes. J Fish Biol 40:963-965

Tapella F, Lovrich GA, Romero MC, Thatje S (2002) Reproductive biology of the crab Munida subrugosa (Decapoda: Anomura: Galatheidae) in the Beagle Channel, Argentina. J Mar Biol Assoc UK 82:589-595

Thiel M, Hinojosa IA (2003) Mating behaviour of the female rock shrimp Rhynchocinetes typus (Decapoda: Caridea) indication for convenience polyandry and cryptic female choice. Behav Ecol Sociobiol 55:113-121

Toonen RJ (2004) Genetic evidence of multiple paternity of broods in the intertidal crab, Petrolisthes cinctipes. Mar Ecol Prog Ser 270:259-263

Urbani N, Sainte-Marie B, Sevigny JM, Zadworny D, Kuhnlein U (1998) Sperm competition and paternity assurance during the first breeding period of female snow crab (Chinoecetes opilio) (Brachyura: Majidae). Can J Fish Aquat Sci 55:1104-1113

Editorial responsibility: Karen Miller, Hobart, Australia
Van Dover CL, Williams AB (1991) Egg size in squat lobsters (Galatheoidea): constraint and freedom. In: Wenner A, Kuris A (eds) Crustacean egg production. Crustacean issues, Vol 7. Balkema, Rotterdam, p 143-156

Wada S, Ashidate M, Goshima S (1997) Observations on the reproductive behaviour of the spiny king crab Paralithodes brevipes (Anomura: Lithodidae). Crustac Res 26: 56-61

> Walker D, Porter BA, Avise JC (2002) Genetic parentage assessment in the crayfish Orconectes placidus, a high fecundity invertebrate with extended maternal brood care. Mol Ecol 11:2115-2122

> Wenner EL (1982) Notes on the distribution and biology of Galatheidae and Chirostylidae (Decapoda: Anomura) from the middle Atlantic Bight. J Crustac Biol 2:360-377

Yue GH, Li JL, Wang CM, Xia JH, Wang GL, Feng JB (2010) High prevalence of multiple paternity in the invasive crayfish species Procambarus clarkii. Int J Biol Sci 6: $107-115$

Zainal KAY (1990) Aspects of the biology of the squat lobster Munida rugosa (Fabricius, 1775). PhD dissertation, University of Glasgow

Submitted: July 2, 2010; Accepted: October 26, 2010 Proofs received from author(s): January 5, 2011 